\title{
Finishing precocity visual score and genetic associations with growth traits in Angus beef cattle
}

\author{
D.M. Everling ${ }^{1}$, T. Bresolin ${ }^{2}$, P.R.N. Rorato ${ }^{1}$, R.O. Araujo ${ }^{3}$, \\ A.A. Boligon ${ }^{2}$, T. Weber ${ }^{1}$, M.A. Dornelles ${ }^{1}$ and L.T. Campos ${ }^{4}$ \\ ${ }^{1}$ Departamento de Zootecnia, Universidade Federal de Santa Maria, \\ Santa Maria, RS, Brasil \\ ${ }^{2}$ Departamento de Zootecnia, Faculdade de Ciências Agrárias e Veterinárias, \\ Universidade Estadual Paulista, Jaboticabal, SP, Brasil \\ ${ }^{3}$ Programa de Pós-Graduação em Ciência Animal, \\ Universidade Nacional de Brasília, Campus Universitário Darcy Ribeiro, \\ Brasília, DF, Brasil \\ ${ }^{4}$ Associação Nacional de Criadores Herd Book Collares, Pelotas, RS, Brasil \\ Corresponding author: T. Bresolin \\ E-mail: t_bresolin@zootecnista.com.br
}

Genet. Mol. Res. 13 (3): 7757-7765 (2014)

Received August 2, 2013

Accepted July 6, 2014

Published September 26, 2014

DOI http://dx.doi.org/10.4238/2014.September.26.13

\begin{abstract}
Finishing precocity visual score selection was adopted to estimate the time from birth to reach slaughter age. This study estimated (co)variance components and genetic correlations for the finishing precocity score at weaning (WP) and yearling (YP) stages by using daily weight gain $(\mathrm{BWG}=$ from birth to weaning; WYG = from weaning to yearling) and speed of weight gain $(B W R=$ from birth to weaning; WYR = from weaning to yearling) as support for a genetic evaluation program for Angus beef cattle. Genetic parameters were estimated using Bayesian inference, considering multi-trait analysis and assuming a nonlinear model for WP and YP and linear model for
\end{abstract}


all other traits. Direct heritability estimates were 0.17 (WP), 0.19 (YP), 0.15 (BWG), 0.16 (WYG), 0.15 (BWR), and 0.16 (WYR). The genetic correlation between the finishing precocity score at two ages (weaning and yearling) was 0.61 . Positive and moderate genetic correlations were obtained between WP and BWG (0.47) and WP and BWR (0.46). In contrast, negative and low genetic associations were estimated between WP and yearling growth traits (-0.16, WYG; -0.15 , WYR). Genetic correlations between YP and other traits were positive 0.29 (BWG), 0.28 (BWR), 0.48 (WYG), and 0.47 (WYR). The selection response for the finishing precocity score at weaning and yearling ages would be low. Selection to increase WP and YP should result in favorable genetic changes in daily weight gains as a correlated response. Therefore, to obtain animals suited for beef cattle production systems, finishing precocity score and growth traits should be considered as selection criteria.

Key words: Beef cattle; Gibbs sampling; Monte Carlo method; Threshold models

\section{INTRODUCTION}

In beef cattle, growth traits measurements at standard ages have been used as selection criteria to improve animal growth during certain periods. However, weights or weight gains at certain ages are insufficient to evaluate animal yield and carcass quality at the time of slaughter. One way to measure the finishing precocity is the attribution of visual scores, which are easy to obtain. This score considers subcutaneous fat deposition and permits the evaluation of early or late finishing. In general, finishing precocity scores have medium to high heritability (Cardoso et al., 2001; Weber et al., 2009a; Boligon and Albuquerque, 2010 ), indicating the possibility of obtaining genetic gain by selection. Nonetheless, few studies have estimated the genetic correlations between the finishing precocity and other traits of interest.

The choice of the selection method and the genetic progress depends on the knowledge of genetic parameters, such as heritability and genetic correlations in populations (Cardoso et al., 2001). Thus, genetic association studies of the finishing precocity and growth traits will provide details that contribute to better planning of the objectives and selection criteria to be used in commercial beef cattle herds to identify genotypes that are better suited to the farming system.

In the genetic evaluation of visual scores, data do not show a normal distribution. According to Marcondes et al. (2005), threshold models should be used for categorical traits because they detect genetic variability easier when compared to linear models. Thus, the use of methodologies to obtain genetic correlations between categorical (visual scores) and continuous (weights or weight gain) traits through multi-trait analyses using Bayesian inference is recommended.

The objective of this study was to estimate heritability and genetic associations of the finishing precocity score at weaning and yearling stages by using daily weight gain from birth 
to weaning, daily weight gain from weaning to yearling, speed of weight gain from birth to weaning, and speed of weight gain from weaning to yearling to provide support for a genetic evaluation program for Angus beef cattle.

\section{MATERIAL AND METHODS}

\section{Data editing and contemporary groups}

Data were collected routinely by the Beef Cattle Improvement Program (PROMEBO) of the National Association of Breeders: Herd Book Collares (ANC). Records of finishing precocity visual scores and weight at weaning and yearling were considered. Animals without a birth weight measure and/or uncertain paternity were excluded. For all traits, records of 13,852 Angus breed animals, progenies of 382 sires and 9424 cows, born between 1994 and 2009 were used. The relationship matrix consisted of 22,290 animals. The traits evaluated were as follows: finishing precocity score at weaning (WP) and at yearling (YP), average daily weight gain from birth to weaning (BWG) and from weaning to yearling (WYG) and weight gain rate from birth to weaning (BWR) and from weaning to yearling (WYR).

Score evaluation was performed visually, and the animals were scored from one to five. The finishing precocity evaluates the ability of an animal to reach a minimum carcass finishing, with not necessarily high weights. Animals with good depth of ribs and with subcutaneous fat deposits in certain regions of the body receive higher scores. Thus, in each group, the median animals for each trait are used as comparison and receive the score three. In the dataset, $2.5,15.5,38.9,31.8$, and $11.3 \%$ of animals received WP scores of $1,2,3$, 4, and 5 , respectively, and 2.7, 14.9, 38.1, 32.7, and 11.6\% of animals received YP scores of 1, 2, 3, 4, and 5 , respectively.

The BWG was obtained by dividing the weight gain in the period until weaning and the age of the animal at the time of weighing using the following equation: $\mathrm{BWG}=(\mathrm{WW}-$ $\mathrm{BW}) / \mathrm{WA}$, in which $W W=$ weaning weight, $B W=$ birth weight, and $W A=$ weaning age. Likewise, WYG was obtained using the ratio between the gain in the period and the number of days between weighing at weaning and at yearling by the following equation: $\mathrm{WYG}=(\mathrm{YW}-\mathrm{WW})$ / (YA - WA), in which $Y W=$ yearling weight and $Y A=$ yearling age.

To express the growth rate, the BWR and WYR variables were created. The BWR trait was established considering one animal with a birth weight of about $30 \mathrm{~kg}$ and a weaning weight of $190 \mathrm{~kg}$. Thus, this animal had to be able to gain $160 \mathrm{~kg}$ during this period. In the same way, the WYR variable was established to foresee an animal that would quickly reach a yearling weight of $330 \mathrm{~kg}$ to be finished in confinement. This animal would need to gain $140 \mathrm{~kg}$ post-weaning, considering a weaning weight of $190 \mathrm{~kg}$. Higher scores were attributed to animals with higher precocity than the less precocious animals. The equations were as follows: $\mathrm{BWR}=1000 /(160 / \mathrm{BWG})$ and WYR $=1000 /(140 / \mathrm{WYG})$. This variable presented a normal distribution with values between one (less precocious animal) and 12 (more precocious animal). The birth, weaning, and yearling seasons were divided into four classes: January to March, April to June, July to September, and October to December.

For WP, the systematic effects of the weaning contemporary group (WCG) (farm + sex + birth year + birth season + management group + weaning season) and the linear and quadratic covariates of animal age at measurement and age of dam at calving were consid- 
ered. For YP, the systematic effects of the yearling contemporary group (YCG) (farm + sex + birth season + management group + weaning season + yearling season) and animal age at measurement, as a covariate (linear and quadratic effects), were considered. For BWG and BWR, the systematic effects of WCG and age of dam at calving (AC), as a covariate (linear and quadratic effects), were considered. For WYG and WYR, YCG was considered as a systematic effect.

For all traits, contemporary groups with less than 10 information and sires with less than 10 progenies were excluded. Animals with weights of 3.5 standard deviations above or below the average of their contemporary group were also excluded. Table 1 shows a summary of the final data structure.

Table 1. Summary of visual scores and growth traits in Angus cattle.
\begin{tabular}{lccccc}
\hline Traits & Means & Standard deviation & Minimum & Maximum & Contemporary groups \\
\hline WP & - & - & 1 & 5 & 508 \\
YP & - & - & 1 & 5 & 497 \\
BWG & 0.672 & 0.173 & 0.205 & 1.477 & 508 \\
WYG & 0.459 & 0.209 & 0.150 & 1.400 & 597 \\
BWR & 4.205 & 1.083 & 1.286 & 9.233 & 497 \\
WYR & 3.284 & 1.499 & 0.371 & 10.011 & 497 \\
\hline
\end{tabular}

$\mathrm{WP}=$ finishing precocity score at weaning; $\mathrm{YP}=$ finishing precocity score at yearling; $\mathrm{BWG}=$ average daily weight gain from birth to weaning; $\mathrm{WYG}=$ average daily weight gain from weaning to yearling; $\mathrm{BWR}=$ speed of weight gain from birth to weaning; and WYR = speed of weight gain from weaning to yearling.

\section{Heritabilities and genetic correlations}

Heritabilities and genetic correlations were estimated using the Bayesian method in two multi-trait analyses considering evaluations at weaning and at yearling using an animal model. The first multi-trait analysis included the variables WP, YP, BWG, and WYG, and the second included WP, YP, BWR, and WYR.

The animal model included direct additive genetic, maternal genetic (for traits obtained at weaning), and residual effects as random. The systematic effects varied according to the trait being considered.

The general models can be represented using $y=X \beta+Z a+W m+\varepsilon$, where $y$ is the vector of observations for each trait (WP, YP, BWG, WYG, BWR, and WYR), $X$ is the incidence matrix of the systematic effects (WCG, YCG, and AC), $\beta$ is the vector of systematic effects, $Z$ is the incidence matrix of the direct additive genetic effect of each animal, $a$ is the vector of the direct additive genetic effect, $W$ is the incidence matrix of the maternal genetic effect, $m$ is the vector of the maternal genetic effect, and $\varepsilon$ is the vector of the random residual effects.

Random genetic maternal effects were only included in the model for weaning traits; hence, the matrix $W$ and the vector $m$ were absent in the models of the measured traits after weaning. The maternal permanent environment effect was not included in the model because of the reduced number of offspring per dam (1.47).

Two multi-trait analyses were performed with categorical and continuous variables. According to the Bayesian approach, the vectors $\beta, a$, and $m$ are location parameters of a con- 
ditional distribution $y \mid \beta, a, m$.

In the mixed model used, $\beta$ is considered the vector of solutions for the systemic effects; however, from the Bayesian point of view, it is a vector of random effects in which the initial distribution values have uninformative priors, so they do not provide much information about the parameter and, therefore, have a uniform probability distribution. This kind of probability distribution indicates the same probability of occurrence of each of the possible variable values. Inverted Wishart distributions were assigned to the other components. The distribution of $y$, given the parameters of location and scale, was considered as $y \mid \beta, a, m, R \sim$ $\mathrm{N}[X \beta+Z a+W m+I R]$.

To obtain independent or uncorrelated samples, it is necessary to eliminate results of intermediate cycles of the sample chain. The sampling interval is called interval of sampling usage and must be sufficient for the samples used do not be correlated (Faria et al., 2007). The period of disposal and the interval of sampling use were carried out in accordance with the Raftery and Lewis (1992) test using the Bayesian Output Analysis packet of the R software, version 2.10.1 (Smith, 2007).

The combination of the traits in the threshold-linear model was performed with the THRGIBBSF90 computer program (Misztal et al., 2008), which allows the study of categorical and continuous traits in the same analysis. In this study, a chain of 600,000 cycles and burn-in period of 100,000 cycles was implemented. In this first step, samples were taken every 40 cycles to avoid the generated file being very large.

\section{Convergence criteria}

The process of resampling was performed using POSTGIBBSF90 (Misztal et al., 2008). In this step, 100,000 initial samples were discarded, the interval of sampling usage was of 120 , and 4167 samples were obtained to perform the inference. These samples of (co)variances were edited to calculate the heritability estimates and genetic correlations for the traits evaluated.

The file generated was submitted to analyses by the GIBANAL program (Van Kaam, 1998) to diagnose the convergence of the chain and to obtain the effective number of samples, the joint a posteriori densities, and the descriptive statistics. The convergence of the Markov chain was verified through the criteria of Heidelberger and Welch (1983), and the criterion of Geweke (1992) was used to verify the columns that represent the values of the variances of the traits.

\section{RESULTS AND DISCUSSION}

The Monte Carlo error for heritability estimates was very small in all analyses, indicating that the size of the Gibbs chain was sufficient to obtain accurate a posteriori means estimates (Tables 2, 3, and 4).

The a posteriori direct heritability means of all traits obtained at weaning and yearling were low in magnitude and ranged from 0.15 to 0.19 (Table 2). The maternal heritability means ranged from 0.09 to 0.18 . For the maternal genetic effect, except WP, which showed a low value, estimates of heritability were of moderate magnitude and very close to the values obtained for the direct effect. These results indicated the importance of including this effect 
for traits measured at weaning and that the selection for cows with greater maternal ability will promote genetic improvements regarding growth traits in this phase. Therefore, it should be considered in this breed genetic evaluation.

Weber et al. (2009a) obtained lower heritability estimates for visual scores of weaning precocity, both for the direct (0.12) and maternal (0.08) effects when they evaluated data from an Angus population that was established in Rio Grande do Sul. Similar values were obtained for precocity scores (0.16) by Costa et al. (2008) with Brangus cattle; however, these authors did not include the maternal effect in the analyses. Interestingly, these authors used the restricted maximum likelihood method, and, according to Resende et al. (2001), the results tend to be very similar using both approaches when initial priors are considered to add little information in the use of Bayesian inference, which was used in this study. Using Bayesian inference, Araujo et al. (2010) estimated the heritability for the weaning precocity trait, which was similar ( 0.16 for direct effect and 0.09 for maternal effect) to those found in this study.

Heritability estimates for BWG and BWR were very close (Table 2), indicating that if there was direct selection for either of these traits, the genetic gain with the passage of generations should also be similar. Likewise, at yearling, the WYG and WYR traits had very close heritability estimates.

Table 2. Heritability estimates for finishing precocity scores and growth traits in Angus cattle.

\begin{tabular}{|c|c|c|c|c|c|}
\hline Heritability & Mean & Mode & Median & $95 \% \mathrm{CI}$ & MCE \\
\hline \multicolumn{6}{|l|}{ Weaning } \\
\hline $\mathrm{h}^{2} \mathrm{WP}$ & 0.171 & 0.187 & 0.177 & 0.128 to 0.230 & 0.0004 \\
\hline $\mathrm{h}^{2^{\mathrm{d}}} \mathrm{WP}$ & 0.089 & 0.087 & 0.089 & 0.058 to 0.120 & 0.0002 \\
\hline $\mathrm{h}^{2}{ }_{\mathrm{d}}^{\mathrm{m}} \mathrm{BWG}$ & 0.157 & 0.151 & 0.155 & 0.118 to 0.201 & 0.0004 \\
\hline $\mathrm{h}^{2}{ }_{\mathrm{m}}^{\mathrm{d}} \mathrm{BWG}$ & 0.179 & 0.169 & 0.176 & 0.138 to 0.222 & 0.0003 \\
\hline $\mathrm{h}_{\mathrm{d}}^{2 \mathrm{~m}} \mathrm{BWR}$ & 0.156 & 0.155 & 0.154 & 0.112 to 0.207 & 0.0004 \\
\hline $\mathrm{h}_{\mathrm{m}}^{2} \mathrm{BWR}$ & 0.183 & 0.183 & 0.182 & 0.139 to 0.223 & 0.0003 \\
\hline \multicolumn{6}{|l|}{ Yearling } \\
\hline $\mathrm{h}_{\mathrm{d}}^{2} \mathrm{YP}$ & 0.195 & 0.202 & 0.196 & 0.154 to 0.246 & 0.0004 \\
\hline $\mathrm{h}^{2}{ }_{\mathrm{d}}^{\mathrm{d}} \mathrm{WYG}$ & 0.160 & 0.161 & 0.160 & 0.120 to 0.208 & 0.0003 \\
\hline $\mathrm{h}^{2}{ }_{\mathrm{d}}^{\mathrm{d}}$ WYR & 0.162 & 0.165 & 0.162 & 0.119 to 0.209 & 0.0003 \\
\hline
\end{tabular}

$\mathrm{h}_{\mathrm{d}}^{2}=$ direct heritability; $\mathrm{h}_{\mathrm{m}}{ }_{\mathrm{m}}=$ maternal heritability; $\mathrm{CI}=$ confidence interval; $\mathrm{MCE}=$ Monte Carlo error; $\mathrm{WP}=$ precocity score at weaning; $\mathrm{BWG}=$ average daily weight gain from birth to weaning; $\mathrm{BWR}=$ speed of weight gain from birth to weaning; $\mathrm{YP}=$ precocity at yearling; $\mathrm{WYG}=$ average daily weight gain from weaning to yearling, and $\mathrm{WYR}=$ speed of weight gain from weaning to yearling.

In general, the finishing precocity score at yearling showed a low-magnitude heritability compared to that of studies using Nellore cattle and the restricted maximum likelihood method (Koury Filho et al., 2009) and Bayesian inference (Pires et al., 2010; Boligon and Albuquerque, 2010; Boligon et al., 2011). However, low heritability estimates for finishing precocity scores at yearling were observed in a study of Angus cattle that was carried out by Weber (2009b) using a different analysis method. This suggested that the additive genetic variability was reduced relative to the total variance of this trait, which resulted in low heritability estimates in this population.

The genetic correlation that was estimated between finishing precocity scores in the two phases was positive and moderate $(0.61)$, indicating that the selection for finishing precocity at weaning can be conducted successfully with a favorable response also at yearling. This result was expected because the finishing precocity at weaning contained the yearling 
evaluation; it was not possible to separate the evaluation at weaning from that at yearling, but it was possible to separate the weight trait because the weight gain can be determined at each stage of evaluation.

When studying the genetic associations between the finishing precocity score and the other traits, YP presented a positive genetic correlation with the maternal effect for all growth traits at weaning ( 0.31 to 0.39 ). However, the genetic correlation between WP and the maternal effect was negative, and that between WP and growth traits, although positive, was very low, mainly at yearling (Tables 3 and 4). Cardoso et al. (2004) estimated a genetic correlation of 0.60 between weight gains that were adjusted for 205 days and finishing precocity scores at yearling. According to the results obtained, when considering both production phases that were evaluated, it is preferable to select the precocity at yearling because favorable responses also occurred for the maternal effect, which has great importance for the traits that were evaluated until weaning.

Table 3. Genetic correlations between the finishing precocity at weaning and growth traits in Angus cattle.

\begin{tabular}{|c|c|c|c|c|c|}
\hline \multirow[t]{2}{*}{ Genetic correlations } & Means & Mode & Median & $95 \% \mathrm{CI}$ & MCE \\
\hline & \multicolumn{5}{|c|}{ Finishing precocity at weaning } \\
\hline $\mathrm{WP}_{\mathrm{m}}$ & -0.447 & -0.441 & -0.398 & -0.612 to 0.220 & 0.0014 \\
\hline $\mathrm{BWG}$ & 0.467 & 0.460 & 0.466 & 0.271 to 0.620 & 0.0014 \\
\hline BWG & -0.264 & -0.241 & -0.265 & -0.472 to -0.252 & 0.0017 \\
\hline BWR ${ }^{m}$ & 0.456 & 0.477 & 0.462 & 0.278 to 0.619 & 0.0013 \\
\hline $\mathrm{BWR}_{\mathrm{m}}$ & -0.273 & -0.256 & -0.277 & -0.478 to -0.012 & 0.0018 \\
\hline $\mathrm{YP}^{\mathrm{m}}$ & 0.607 & 0.607 & 0.607 & 0.444 to 0.733 & 0.0014 \\
\hline WYG & -0.157 & -0.154 & -0.155 & -0.367 to 0.070 & 0.0018 \\
\hline WYR & -0.150 & -0.138 & -0.144 & -0.374 to 0.050 & 0.0016 \\
\hline
\end{tabular}

$\mathrm{m}=$ maternal effect. For other abbreviations, see legend to Table 2.

Table 4. Genetic correlations between the finishing precocity at yearling and growth traits in Angus cattle.

\begin{tabular}{|c|c|c|c|c|c|}
\hline \multirow[t]{2}{*}{ Genetic correlation } & Mean & Mode & Median & $95 \% \mathrm{CI}$ & MCE \\
\hline & \multicolumn{5}{|c|}{ Finishing precocity at yearling } \\
\hline$\overline{\mathrm{WP}_{\mathrm{m}}}$ & 0.312 & 0.333 & 0.324 & 0.129 to 0.519 & 0.0016 \\
\hline BWG & 0.288 & 0.292 & 0.291 & 0.068 to 0.490 & 0.0017 \\
\hline $\mathrm{BWG}_{\mathrm{m}}$ & 0.395 & 0.375 & 0.396 & 0.288 to 0.556 & 0.0013 \\
\hline $\mathrm{BWR}^{\mathrm{m}}$ & 0.279 & 0.278 & 0.278 & 0.057 to 0.478 & 0.0017 \\
\hline BWR & 0.384 & 0.378 & 0.382 & 0.218 to 0.546 & 0.0015 \\
\hline WYG & 0.481 & 0.452 & 0.471 & 0.323 to 0.601 & 0.0011 \\
\hline WYR & 0.471 & 0.474 & 0.472 & 0.326 to 0.609 & 0.0011 \\
\hline
\end{tabular}

For other abbreviations, see legend to Table 2.

Although Cardoso et al. (2004) recommended the use of visual scores in only one phase of the animal's life, giving preference to the weaning phase, the low genetic association between scores at this stage and growth traits at yearling should be further investigated, because the genetic association with average daily gain or speed of gain was negative. Thus, an unfavorable correlated response is expected for the maternal effect for the traits of average daily gain, gain speed, and finishing precocity. The selection of YP should promote a favorable response for both the maternal effect and the direct effect for all traits at weaning and at 
yearling stages.

For Nellore cattle, Koury Filho et al. (2010) reported a genetic correlation between weight at weaning and finishing precocity at weaning of 0.97. Araujo et al. (2010) and Costa et al. (2008) showed genetic correlations between precocity scores of 0.47 and 0.65 for weight and weight gain from birth to weaning, respectively, in Angus Nellore crossbred bovines. When considering the phases separately, independent of the growth trait to be selected, there will be a positive correlated response for the scores because these correlations between the direct effects do not vary much at weaning nor at yearling.

The genetic correlations between WP and growth traits at weaning were very similar, indicating that if the selection is targeted for BWG or BWR, the same correlate response should be expected for precocity scores because both have a very similar heritability. Because of the great economic relevance of precocity trait indicators, studies regarding the association between scores and less subjective traits measured in different phases of the animal's life should be carried out.

\section{CONCLUSION}

The selection response for finishing precocity scores evaluated at weaning and yearling would be low. The selection for precocity scores may be more effective if applied at yearling because of the higher heritability and positive correlations with the maternal effect for growth traits at weaning. The selection for increased WP and YP should result in favorable genetic changes in daily weight gains as a correlated response. Therefore, to obtain animals suited to beef cattle production systems, finishing precocity scores and growth traits should be considered as selection criteria.

\section{ACKNOWLEDGMENTS}

We would like to thank the National Association of Breeders Herd Book Collares (ANC) for providing the database and Departamento de Zootecnia, USP, Pirassununga and Departamento de Física, UFSM, Santa Maria, for data analysis. The authors thank Capes for granting a scholarship and fellowship to D.M. Everling.

\section{REFERENCES}

Araujo RO, Rorato PRN, Weber T, Everling DM, et al. (2010). Genetic parameters and phenotypic and genetic trends for weight at weaning and visual scores during this phase estimated for Angus-Nellore crossbred young bulls. Rev. Bras. Zootec. 39: 2398-2408.

Boligon AA and Albuquerque LG (2010). Correlações genéticas entre escores visuais e características reprodutivas em bovinos Nelore usando inferência Bayesiana. Pesq. Agropec. Bras. 45: 1412-1418.

Boligon AA, Mercadante MEZ and Albuquerque LG (2011). Genetic associations of conformation, finishing precocity and muscling visual scores with mature weight in Nelore cattle. Livest. Sci. 135: 238-243.

Cardoso FF, Cardellino RA and Campos LT (2001). Componentes de (co)variância e parâmetros genéticos para caracteres produtivos à desmama de bezerros Angus criados no Estado do Rio Grande do Sul. Rev. Bras. Zootec. 30: 41-48.

Cardoso FF, Cardellino RA and Campos LT (2004). Componentes de (co)variância e parâmetros genéticos de caracteres pós-desmama em bovinos da raça Angus. Rev. Bras. Zootec. 33: 313-319.

Costa GZ, Queiroz AS, Oliveira JA and Fries LA (2008). Estimativas de parâmetros genéticos e fenotípicos de escores visuais e de ganho médio de peso do nascimento à desmama de bovinos formadores da raça Brangus. Ars. Vet. 24: 
$172-176$

Faria CU, Magnabosco CU, Los Reyes A, Lôbo RB, et al. (2007). Inferência Bayesiana e sua aplicação na avaliação genética de bovinos da raça nelore: revisão bibliográfica. Ciênc. Anim. Bras. 8: 75-86.

Geweke J (1992). Evaluating the accuracy of sampling-based approaches to the calculation of posterior moments. In: Bayesian statistics (Bernardo JM, Berger JO, Dawid AP and Smith AFM, eds.). Oxford University, New York, 625-631.

Heidelberger P and Welch PD (1983). Simulation run length control in the presence of an initial transient. Oper. Res. 31: 1109-1144.

Koury Filho W, Albuquerque LG, Alencar MM, Forni S, et al. (2009). Estimativas de herdabilidade e correlações para escores visuais, peso e altura ao sobreano em rebanhos da raça Nelore. Rev. Bras. Zootec. 38: 2362-2367.

Koury Filho W, Albuquerque, LG, Forni S, Silva JAV, et al. (2010). Estimativas de parâmetros genéticos para os escores visuais e suas associações com peso corporal em bovinos de corte. Rev. Bras. Zootec. 39: 1015-1022.

Marcondes CR, Paneto JCC, Silva JAV, Oliveira H, et al. (2005). Comparação entre análises para permanência no rebanho de vacas Nelore utilizando modelo linear e modelo de limiar. Arq. Bras. Med. Vet. Zootec. 57: 234-240.

Misztal I, Tsuruta S, Strabel T, Auvray B, et al. (2008). BLUPF90 family of programs. Available at [http://nce.ads.uga. edu/ ignacy/newprograms.html]. Accessed May 10, 2011.

Pires BC, Faria CU, Viu MAO, Terra JP, et al. (2010). Modelos Bayesianos de limiar e linear na estimação de parâmetros genéticos para características morfológicas de bovinos da raça Nelore. Rev. Bras. Saúde Prod. Anim. 11: 651-661.

Raftery AE and Lewis S (1992). Comment: one long run with diagnostics: implementation strategies for Markov chain Monte Carlo. Stat. Sci. 7: 493-497.

Resende MDV, Duda LL, Guimarâes PRB and Fernandes JSC (2001). Análise de modelos lineares mistos via inferência bayesiana. Rev. Mat. Estatist. 19: 41-70.

Smith BJ (2007). boa: an R package for MCMC output convergence assessment and posterior inference. J. Stat. Soft. 21: 1-37.

Van Kaam JBCHM (1998). Gibanal 2.9: analyzing program for Markov chain Monte Carlo sequences. Department of Animal Science, Agricultural University, Wageningen. Available at [http://nce.ads.uga.edu/ ignacy/newprograms. html]. Accessed February 14, 2012.

Weber T, Rorato PRN, Lopes JS, Comin JG, et al. (2009a). Parâmetros genéticos e tendências genéticas e fenotípicas para características produtivas e de precocidade na fase pré-desmama em uma população da raça Aberdeen Angus. Rev. Bras. Zootec. 38: 832-842.

Weber T, Rorato PRN, Lopes JS, Comin JG, et al. (2009b). Parâmetros genéticos e tendências genéticas e fenotípicas para escores visuais na fase pós-desmama de bovinos da raça Aberdeen Angus. Cienc. Rural. 39: 832-837. 